\title{
Effect of Dual Inoculation of Arbuscular Mycorrhiza and Rhizobium on the Chlorophyll, Nitrogen and Phosphorus Contents of Pigeon Pea (Cajanus cajan L.)
}

\author{
Sujata Bhattacharjee*, Gouri Dutta Sharma \\ Department of Life Science and Bioinformatics, Assam University, Silchar, India \\ Email: "bhattacharjee.sujata819@gmail.com
}

Received August 27, 2012; revised October 8, 2012; accepted October 17, 2012

\begin{abstract}
The pot experiments were conducted in the Department of Life Science and Bioinformatics of Assam University, Silchar. The aim of the present study was to investigate the effect of dual inoculation of Arbuscular mycorrhiza (AM) (Glomus fasciculatum) and Rhizobium on the chlorophyll, nitrogen and phosphorus contents of pigeon pea (Cajanus cajan L.). The results revealed an overall increase in chlorophyll, nitrogen and phosphorus contents in the inoculated plants than uninoculated ones. Maximum chlorophyll contents were recorded in the plants dually inoculated with Glomus fasciculatum and Rhizobium. The combined application of Glomus fasciculatum and Rhizobium also remarkably increased the nitrogen and phosphorus contents of pigeon pea. The dual inoculation with microsymbionts revealed synergistic effect. The results suggest that dual inoculation of Glomus fasciculatum and Rhizobium have the potential to enhance the chlorophyll, nitrogen and phosphorus contents of pigeon pea.
\end{abstract}

Keywords: Glomus fasciculatum; Rhizobium; Dual Inoculation; Chlorophyll; Nitrogen; Phosphorus

\section{Introduction}

Symbiosis is a biological phenomenon involving dynamic changes in the genome metabolism and signaling network [1]. Most of the legumes possess two types of microbial symbionts namely mycorrhizal fungi and nitrogen fixing bacteria thereby establishing triple association, capable of supplying $\mathrm{N}$ and $\mathrm{P}$ contents to the plants [2]. Both the mycorrhizal fungi and Rhizobium act as biofertilizer and have the unique ability to convert nutriationally important elements from unavailable to available form through biological process [3,4].

Pigeon pea (Cajanus cajan L.), commonly known as Arhar, a protein rich pulse crop has growing demand in Asia, specially in India because it can provide high quality protein in Indian diet. The plant has got immense medicinal value and is also used as fodder for cattle. There is need to enhance its productivity to meet the demand of growing population. Barak valley of Assam is legging behind in the production of pigeon pea in comparison with rest part of India. Researches in the past few decades on various aspects of root symbionts have shown that dual interaction of AM fungi and Rhizobium has improved the growth, nodulation and yield $[5,6]$ and also nutrient status [6,7] in legumes. Increased nitrogen fixa-

${ }^{*}$ Corresponding author. tion in Chickpea due to dual inoculation with G. fasciculatum and Rhizobium was reported by Subba Rao et al., 1985 [8]. In the light of these views, an attempt has been made in the present study, to investigate the effect of dual inoculation of AM fungus (Glomus fasciculatum) and Rhizobium in chlorophyll, nitrogen and phosphorus contents of pigeon pea.

\section{Materials and Methods}

The present study was carried out at the Department of Life Science and Bioinformatics of Assam University, which is located in Silchar, Assam (India), between $23^{\circ} \mathrm{N}$ to $24^{\circ} \mathrm{N}$ latitude and between $92^{\circ} \mathrm{E}$ to $93^{\circ} \mathrm{E}$ longitude. Four treatments were performed in the present work as followed:

1) Inoculation with Glomus fasciculatum alone.

2) Inoculation with Rhizobium alone.

3) Dual inoculation with Glomus fasciculatum and Rhizobium.

4) Uninoculated plants considered as control.

\section{Preparation of Inoculum}

\subsection{Inoculation with Glomus Fasciculatum Alone}

Glomus fasciculatum was isolated from the rhizospheric soil of pigeon pea by wet sieving and decanting tech- 
nique [9] and multiplied on the roots of Zea mays plants. The plants were allowed to grow for three months after which the roots were severed and the substrate containing root fragments, mycelium and spores were collected and air dried and used as inoculum. Healthy seeds of pigeon pea were surface sterilized with $0.2 \%$ mercuric chloride for 5 minutes and were washed several times with sterile distilled water. The seeds were germinated in the mixture of sterilized soil under dark condition. The seedlings were allowed to grow for 10 days. Seedlings of uniform height were transplanted in plastic pots containing $2 \mathrm{~kg}$ oven sterilized mixure of sand and soil in the ratio 1:1. Seedlings were inoculated with mycorrhizal inoculum containing maize root fragments, mycelium and spores (100 g per pot). The treatment was replicated ten times (one seedling in each pot).

\subsection{Inoculation with Rhizobium Alone}

The Rhizobium isolates were obtained from root nodules of pigeon pea. Healthy, pinkish, well formed, unbroken nodules were collected from the roots of pigeon pea. The nodules were surface sterilized for 3 minutes in $0.1 \%$ mercuric chloride and washed repeatedly with sterile water. Individual nodules were crushed with sterile glass rods in a small aliquot of sterile water and milky fluid was streaked on to sterile Yeast Extract Manitol Agar (YEMA) containing Congo red $(2.5 \mathrm{~mL}$ of $1 \%$ Congo red in $100 \mathrm{~mL}$ YEMA). The plates were incubated at $28^{\circ} \mathrm{C}$ for 5 days. Colonies were selected and streaked on YEMA for purity and pure culture of isolated bacteria was subjected to morphological and biochemical (growth on Hofers alkaline medium, growth on Glucose peptone agar) test for characterization as described by Subba Rao, 1999 [10]. For inoculation, healthy, sterilized seeds of pigeon pea were suspended in 20 - $40 \mathrm{~mL}$ thick suspension $\left(10^{9}\right.$ cells $\left./ \mathrm{mL}\right)$ of Rhizobium for 30 minutes. The seeds were air dried for 30 minutes in sterile Petri plates. The seedlings were allowed to grow for 10 days. Seedlings of uniform height were transplanted in plastic pots (one in each pot) containing $2 \mathrm{Kg}$ oven sterilized mixture of sand and soil in the ratio (1:1). The treatment was replicated ten times (one seedling in each pot).

\subsection{Inoculation with Glomus fasciculatum and Rhizobium in Combination (Dual Inoculation)}

For combined inoculation with Glomus fasciculatum and Rhizobium, 10 days old seedlings grown in dark condition (seeds were pre inoculated with Rhizobium) were transplanted in plastic pots containing mycorrhizal inoculum. The treatment was replicated ten times (one seedling in each pot).

\subsection{Uninoculated Plants (Control)}

For control, sterilized seeds were grown in dark condition for 10 days and seedlings of uniform height were transplanted into pots containing $2 \mathrm{Kg}$ of mixture of sterilized soil and sand mixed in the ratio (1:1). The treatment was replicated ten times (one seedling in each pot).

The experiment was laid out in randomized complete block (RCB) design. Plants were watered everyday.

\subsection{Determination of Chlorophyll Contents of Leaves}

Three replicates at random from each treatment were selected for determination of chlorophyll content of leaves. Chlorophyll content of leaves was determined after 120 days of inoculation of plants. Chlorophyll contents were separated and estimated following the method as described by Sadasivan and Manickam, 1996 [11]. Chlorophyll was extracted in $80 \%$ acetone and total chlorophyll contents were calculated with the formula

$$
\begin{aligned}
& \text { Total chlorophyll content }\left(\mathrm{mg} \cdot \mathrm{g}^{-1}\right) \\
& =20.2\left(\mathrm{~A}_{645}\right)+8.02\left(\mathrm{~A}_{663}\right) \frac{\mathrm{V}}{1000 \times \mathrm{W}},
\end{aligned}
$$

where, $\mathrm{A}=$ Absorbance at specific wave length; $\mathrm{V}=$ Final volume of chlorophyll content in $80 \%$ acetone; $\mathrm{W}=$ Fresh weight of the tissue extract.

\subsection{Estimation of Nitrogen and Phosphorus Contents}

Three replicates at random from each treatment were selected for estimation of each of nitrogen and phosphorrus. Dried plant materials were converted to ashes for estimation of Nitrogen and Phosphorus. Nitrogen content of the plant ash was determined by alkaline permanganate method [12] and phosphorus content was determined by Spectrophotometric method [13].

Statistical analysis: The data were subjected to analysis of variance (ANOVA) using SPSS statistical software program (version 7.5) and Critical Difference (CD) was calculated at 5\% level of significance [14].

\section{Results}

On YEMA, circular, cream coloured, sticky and and raised transluscent colonies of bacteria appeared. On YEMA containing Congo red, faint colonies appeared indicating that the isolates were bacterium $[15,16]$. The organism could not grow at $\mathrm{pH} 11.0$ at Hofer's alkaline medium which also indicated that the isolates were bacterium [17]. Moreover, the formation of root nodules at the roots of plants inoculated with bacteria confirmed that the isolates were Rhizobium.

The effects of individual inoculation with both Glomus 
fasciculatum and Rhizobium and their combined inoculation on the chlorophyll content, nitrogen and phosphorus contents of pigeon pea are presented in the Table $\mathbf{1}$. The results presented in the Table 1 revealed that chlorophyll contents in the treated plants were higher than those in control. G. fasciculatum markedly improved the chlorophyll contents in the leaves of pigeon pea. However, maximum chlorophyll contents were recorded in the plants dually inoculated with G. fasciculatum and Rhizobium. VAM fungi have been shown to improve the chlorophyll contents on the leaves of many plants [18-20]. It is evident from the results of the present study that the efficacy of VAM fungi was influenced by co inoculation with Rhizobium. Increase in the chlorophyll contents due to dual inoculation of VAM fungi and Rhizobium might be attributed to increased rate of photosynthesis and transpiration or due to increased growth [21]. Krishna and Bagyaraj, 1984 [22] reported that increase in chlorophyll content in the inoculated plants might be due to presence of large number of chloroplast bundle sheath in the leaves. Dual inoculation of AM fungi and Rhizobium significantly increased chlorophyll contents in Vigna unguiculata (L.) [23] which is supported by the findings of our present study.

The results clearly indicated that inoculation of the plants with both G. fasciculatum and Rhizobium increased the nitrogen and phosphorus contents of pigeon pea. There was overall increase in nitrogen and phosphorus contents in the treated plants as compared to control. However, maximum nitrogen and phosphorus contents were recorded in the plants dually inoculated with G. fasciculatum and Rhizobium. Inoculation of legumes with Rhizobium increase the nodulation of legumes causing more nitrogen fixation and making it available for the plants and therefore, it is used as an alternative for urea to minimize the cost of produce [24]. Moreover, it also increase rhizospheric microflora viz. acid producers and phosphate solubilizers causing more available phosphorus [25]. Rhizobium inoculation has been shown to improve the nitrogen and phosphorus contents of legumes [26] which supported the results of our present findings. One of the most significant effects of my

Table 1. Effect of dual inoculation of Glomus fasciculatum and Rhizobium on the chlorophyll, nitrogen and phosphorus contents of pigeon pea.

\begin{tabular}{cccc}
\hline Microbial Inoculants & Chlorophyll Content (mg/g) & $\mathrm{N}(\%)$ & $\mathrm{P}(\%)$ \\
\hline Uninoculated Control & 2.47 & 3.04 & 0.98 \\
Rhizobium & 2.81 & 3.18 & 1.87 \\
VAM & 2.85 & 3.26 & 2.03 \\
VAM + Rhizobium & 2.94 & 3.34 & 2.1 \\
CD ( p = 0.05 ) & 0.03 & 1.02 & 0.02 \\
\hline
\end{tabular}

corrhizal inoculation on the host plant is the increase in phosphorus uptake [27] due to enhanced capacity to absorb more phosphorus from the soil which is otherwise unavailable to the plants. AM fungi supported nitrogen fixation by providing legumes with phosphorus and other immobile nutrients which are essential for nitrogen fixation [28]. Tavasolee et al., 2011 [29] suggested that effective AM fungi can enhance the performance of rhizobial infection and vice versa which was also evident during our present investigation. The results of the present study indicated that combined inoculation of G. fasciculatum and Rhizobium had a synergistic effect resulting in the improvement of nitrogen and phosphorus.

Many reports are available on the increased nitrogen and phosphorus contents of legumes due to dual inoculation of AM fungi and Rhizobium which are supported by the findings of our present study [7,6,29-31].

Summing up, dual inoculation of G. fasciculatum and Rhizobium increased chlorophyll, nitrogen and phosphorus contents of pigeon pea plant indicating that their combination may have a potential role to enhance the productivity of the plant.

\section{REFERENCES}

[1] M. Kawaguchi and K. Minamisawa, "Plant-Microbe Communications for Symbiosis,” Plant Cell Physiology, Vol. 51, 2010, pp. 1377-1380. doi:10.1093/pcp/pcq125

[2] A. P. D. Silveira and E. J. B. N. Cardoso, “Arbuscular Mycorrhiza and Kinetic Parameters of Phosphorus Absorption by Bean Plants,” Agricultural Science, Vol. 61, 2004, pp. 203-209.

doi:10.1590/S0103-90162004000200013

[3] D. M. Hegde, B. S. Dwivedi and S. N. Sudhakara, "Biofertilizers for Cereal Production in India Review," The Indian Journal of Agricultural Sciences, Vol. 69, 1999, pp. 73-83.

[4] J. K. Vessey, "Plant Growth Promoting Rhizobacteria as Biofertilizers,” Plant Soil, Vol. 255, 2003, pp. 571-586. doi:10.1023/A:1026037216893

[5] T. S. Gill and R. S. Singh, "Effects of Glomus fasciculatum and Rhizobium Inoculation on V.A. Mycorrhizal Colonization and Plant Growth of Chickpea," Indian Phytopathology, Vol. 32, No. 2, 2002, pp. 162-166.

[6] N. B. Talaat and A. M. Abdallah, "Response of Faba Bean (Vicia fava L.) to Dual Inoculation with Rhizobium and VA Mycorrhiza under Different Levels of N and P Fertilization,” Journal of Applied Sciences Research, Vol. 4, No. 9, 2008, pp. 1092-1102.

[7] J. Chakrabarty, N. C. Chatterjee and S. Dutta, "Interactive Effect of VAM and Rhizobium on Nutrient Uptake and Growth of Vigna mungo," Journal of Mycopathology Research, Vol. 45 No. 2, 2007, pp. 289-291.

[8] N. S. Subba Rao, K. V. P. R. Tilak and C. S. Singh, "Synergistic Effect of Vesicular-Arbuscular Mycorrhiza and Azospirillum brasilense on Growth of Barley in 
Pots," Soil Biology \& Biochemistry, Vol. 19, 1985, pp. 119-122. doi:10.1016/0038-0717(85)90101-4

[9] J. W. Gerdemann and T. H. Nicolson, "Spores of Mycorrhizal Endogone Extracted from Soil by Wet Sieving and Decanting," Transactions of the British Mycological Society, Vol. 46, 1963, pp. 235-244. doi:10.1016/S0007-1536(63)80079-0

[10] N. S. Subba Rao, "Rhizobacterium and Legume Root Nodulation," Soil Microbiology, Oxford \& IBH Publishing Co. Pvt. Ltd., New Delhi, 1999, p. 169.

[11] S. Sadasivan and A. Manickam, "Pigments in: Biochemical Methods (2nd Edition),” New Age International (P) Ltd. Publishers, New Delhi, 1996, pp. 190-191.

[12] B. V. Subbiah and G. L. Asija, “A Rapid Procedure for Determination of Available Nitrogen in Soils," Current Science, Vol. 25, 1956, pp. 259-260.

[13] R. H. Bray and L. T. Kurtz, "Determination of Total Organic and Available Forms of Phosphorus in Soils," Soil Science, Vol. 59, 1945, pp. 39-45. doi:10.1097/00010694-194501000-00006

[14] V. G. Panse and P. V. Sukhatme, "Statistical Methods for Agricultural Workers,” 1969.

[15] M. Dye, "Functions and Maintenance of Rhizobium Collection,” In: N. S. Subba Rao, Ed., Recent Advances in Biological Nitrogen Fixation, Oxford and IBM Publishing Co., New Delhi, 1979, pp. 435-471.

[16] J. M. Vincent, "A Manual for the Practical Study of the Root Nodule Bacteria,” IBP Hand Book No. 15, Scientific Publications, Oxford, 1970.

[17] Y. D. Gaur and A. N. Sen, "Cultural and Biochemical Characteristics of Root Nodule Bacteria of Chickpea [Cicer arietinum (L.)]," Zbl Bakt II, Vol. 136, 1981, pp. 307-316.

[18] F. G. Abdel and A. H. Mohamedin, "Interactions between a Vesicular-Arbuscular Mycorrhizal Fungus and Streptomyces and Their Effects on Sorghum Plants," Biology and Fertility of Soils, Vol. 32, 2000, pp. 401-409. doi:10.1007/s003740000269

[19] A. Diaz Franco and I. Garza Cano, “Arbuscular Mycorrhizal Colonization and Growth of Buffel Grass (Cenchrus ciliaris) Genotypes,” Revista Fitotecnia, Vol. 29, 2006, pp. 203-206.

[20] P. Zuccarni, "Mycorrhizal Infection Ameliorates Chlorophyll Content and Nutrient Uptake of Lettuce Exposed to Saline Irrigation,” Plant Soil Environment, Vol. 53, No. 7, 2007, pp. 283-289.

[21] G. Sampathkumar and A. Ganeshkumar, "Effect of AM Fungi and Rhizobium on Growth and Nutrition of Vigna mungo L. and Vigna unguiculata L.,” Mycorrhiza News, Vol. 14, No. 4, 2003, pp. 15-18.
[22] K. R. Krishna and D. J. Bagyaraj, “Growth and Nutrient Uptake of Peanut Inoculated with Mycorrhizal Fungus Glomus fasciculatum Compared with Uninoculated Ones," Plant and Soil, Vol. 77, 1984, pp. 405-408. doi:10.1007/BF02182946

[23] S. Rajasekaran and S. M. Nagarajan, "Effect of Dual Inoculation (AM Fungi and Rhizobium) on Chlorophyll Content of Vigna unguiculata (L)., Walp. Var. Pusa 151," Mycorrhiza News, Vol. 17, No. 1, 2005, pp. 10-11.

[24] M. R. Karim, F. Islam, M. Akkas Ali and F. Haque, “OnFarm Trail with Rhizobium Inoculants on Lentil,” Bangladesh Journal of Agricultural Research, Vol. 26, 2001, pp. 93-94.

[25] J. G. Lipman and A. B. Conybeare. "Preliminary Note on the Inventory and Balance Sheet of Plant Nutrients in the United States,” New Jersey Agricultural Experiment Station Bulletin, 1936, p. 607.

[26] M. H. Abd-Alla and S. A. Omar, "Survival of Rhizobia/ Bradyrhizobia and a Rock-Phosphate Solubilizing Fungus Aspergillus niger on Various Carriers from Some AgroIndustrial Wastes and Their Effects on Nodulation and Growth of Faba Bean and Soybean,” Journal of Plant Nutrition, Vol. 24, 2001, pp. 261-272. doi:10.1081/PLN-100001386

[27] J. F. Bai, X. G. Lin, R. Yin, H. Y. Zhang, J. H. Wang, X. M. Chen and Y. M. Luo, "The Influence of Arbuscular Mycorrhizal Fungi on As and p Uptake by Maize (Zea mays L.) from As-Contaminated Soils,” Applied Soil Ecology, Vol. 38, No. 2, 2008, pp. 137-145. doi:10.1016/j.apsoil.2007.10.002

[28] R. B. Clark and S. K. Zeto, "Mineral Acquisition by Arbuscular Mycorrhizal Plants," Journal of Plant Nutrition, Vol. 23, 2000, pp. 867-902. doi:10.1080/01904160009382068

[29] A. Tavasolee, N. Aliasgharzad, G. Salehijouzani, M. Mardi and A. Asgharzadeh, "Interactive Effects of Arbuscular mycorrhizal Fungi and rhizobial Strains on Chickpea Growth and Nutrient Content in Plant," African Journal of Microbialogy, Vol. 10, 2011, pp. 7585-7591.

[30] M. I. Bhat, A. Rashid, Faisul-ur-Rasool, S. S. Mahdi, S. A. Haq and R. A. Bhat, "Effect of Rhizobium and Vesicular Arbuscular Mycorrhizae Fungi on Green Gram (Vigna radiata L. Wilczek) under Temperate Conditions," Research Journal of Agricultural Sciences, Vol. 1, No. 2, 2010, pp. 113-118.

[31] A. S. Soliman, N. T. Shanan, O. N. Massoud and D. M. Swelim, "Improving Salinity Tolerance of Acacia saligna (Labill.) Plant by Arbuscular Mycorrhizal Fungi and Rhizobium Inoculation," African Journal of Microbialogy, Vol. 11, 2012, pp. 1259-1266. 